\title{
Chemogeography of the red macroalgae Asparagopsis: metabolomics, bioactivity, and relation to invasiveness
}

\author{
Stéphane Greff ${ }^{1}$ Mayalen Zubia ${ }^{2} \cdot$ Claude Payri $^{3} \cdot$ Olivier P. Thomas $^{1,4,5}$. \\ Thierry Perez ${ }^{1}$
}

\begin{abstract}
Introduction The Latitudinal Gradient Hypothesis (LGH) foresees that specialized metabolites are overexpressed under low latitudes, where organisms are subjected to higher herbivory pressure. The widespread macroalga Asparagopsis taxiformis is composed of six distinct genetic lineages, some of them being introduced in many regions.

Objectives To study (i) metabolic fingerprints of the macroalga and (ii) its bioactivity in space and time, both as proxies of its investment in defensive traits, in order to assess links between bioactivities and metabotypes with macroalgal invasiveness.

Methods 289 macroalgal individuals, from four tropical and three temperate regions, were analyzed using untargeted metabolomics and the standardized Microtox ${ }^{\circledR}$ assay.
\end{abstract}

Thierry Perez

thierry.perez@imbe.fr

Stéphane Greff

stephane.greff@imbe.fr

Mayalen Zubia

mayalen.zubia@upf.pf

Claude Payri

claude.payri@ird.fr

Olivier P. Thomas

olivier.thomas@nuigalway.ie

1 IMBE UMR 7263 CNRS / IRD / Aix Marseille Univ / Univ Avignon, Institut Méditerranéen de Biodiversité et d'Ecologie marine et continentale, Station Marine d'Endoume, rue de la Batterie des Lions, 13007 Marseille, France
Results Metabotypes showed a low divergence between tropical and temperate populations, while bioactivities were higher in temperate populations. However, these phenotypes varied significantly in time, with a higher variability in tropical regions. Bioactivities were high and stable in temperate regions, whereas they were low and much variable in tropical regions. Although the introduced lineage two exhibited the highest bioactivities, this lineage could also present variable proliferation fates.

Conclusion The metabolomic approach partly discriminates macroalgal populations from various geographic origins. The production of chemical defenses assessed by the bioactivity assay does not match the macroalgal genetic lineage and seems more driven by the environment. The higher content of chemical defenses in temperate versus tropical populations is not in accordance with the LGH and cannot be related to the invasiveness of the macroalgae.

2 UMR Ecosystèmes Insulaires Océaniens, LabEx-CORAIL, University of French Polynesia, Faa'a, BP6570, 98702 Tahiti, French Polynesia

3 UMR ENTROPIE, LabEx-CORAIL, Institut de Recherche pour le Développement, BPA5, 98848 Noumea, New Caledonia

4 CNRS, OCA, IRD, Géoazur, Université Côte d'Azur, 250 rue Albert Einstein, 06560 Valbonne, France

5 School of Chemistry, Marine Biodiscovery, National University of Ireland Galway, University Road, Galway, Ireland 
Keywords Asparagopsis taxiformis $\cdot$ Macroalgal proliferations - Metabolomics - Transoceanic comparisons · Microtox ${ }^{\circledR} \cdot$ UHPLC-HRMS

\section{Introduction}

Ecologists generally assume that biotic interactions are prominent under tropics (Schemske et al. 2009) where species richness and biomass are considered higher (Brown 2014; Mannion et al. 2014). The latitudinal gradient hypothesis (LGH) states that tropical plants inherit more defensive traits from higher pressures of competition, herbivory and parasitism than their temperate counterparts (Coley and Aide 1991; Coley and Barone 1996; Schemske et al. 2009). The same trend exists in marine ecosystems as temperate macroalgae are consumed overall twice more than the better defended tropical ones (Bolser and Hay 1996). However, the assumption that both biotic interactions and defense metabolism are strongly related to latitudinal gradient, and resulting from co-evolutionary processes, still requires additional evidences (Moles 2013; Moles and Ollerton 2016). Studies did not show any relationship between herbivory pressure and latitudes (Adams et al. 2008; Andrew and Hughes 2005), and an opposite trend has also been demonstrated in some cases (del-Val and Armesto 2010). For instance, phenolic compounds in terrestrial (Adams et al. 2008) and marine ecosystems seem to be equally present under low and high latitudes (Targett et al. 1992; Van Alstyne and Paul 1990).

Chemical traits may also be related to environmental and/or biotic interactions changes (Nylund et al. 2011). Several ecosystems are affected by introduction of nonindigenous species (NIS) which may disrupt biotic interactions (Schaffelke and Hewitt 2007; Simberloff et al. 2013). After the loss of specific competitors, NIS may reallocate the energy originally dedicated to defenses (specialized metabolism) into reproduction and growth (primary metabolism), and succeed in colonized environments (Keane and Crawley 2002). Interactions between NIS and native species may also modify chemical traits as it is argued by the novel weapon hypothesis (NWH) (Callaway and Ridenour 2004). In addition, the production of defensive compounds may also be influenced by several abiotic factors such as temperature (Ivanisevic et al. 2011b; Reverter et al. 2016), light (Cronin and Hay 1996; Deneb 2001; Paul 2006), and nutrient availability (Cronin and Hay 1996). Moreover, internal factors such as reproductive stage (Ivanisevic et al. 2011a; Vergés et al. 2008), ontogeny (Paul et al. 2014) are globally subjected to seasonal variation and consequently they may affect the s pecialized metabolism ( Ivanisevic et al. 2011a).
The genus Asparagopsis (Rhodophyta, Bonnemaisoniaceae) is currently represented by two species, A. taxiformis (Delile) Trévisan de Saint-Léon and A. armata (Harvey) (Andreakis et al. 2004; Dijoux et al. 2014). Asparagopsis taxiformis is widespread in temperate, subtropical and tropical areas and, so far, six cryptic lineages with distinct geographic distributions have been described for this species (Andreakis et al. 2007, 2016; Dijoux et al. 2014). Among them, the worldwide fragmented distribution pattern of $A$. taxiformis lineage two is explained by multiple introduction events, and in some places of the Southwestern Mediterranean Sea for instance, it is clearly invasive and outcompeting indigenous benthic organisms (Altamirano et al. 2008; Zanolla et al. 2011).

The genus Asparagopsis is known to biosynthesize about one hundred of halogenated volatile hydrocarbons containing one to four carbons with antimicrobial, antifeedant and cytotoxic properties (Genovese et al. 2012; Kladi et al. 2004; Paul et al. 2006b). Assessment of resources allocated to defense traits can be obtained through analysis of the specialized metabolism using metabolomics. Another way to evaluate resources allocated to defense traits is to measure the bioactivity of organismal extract as a proxy of defense-related compounds biosynthesis. The Microtox ${ }^{\circledR}$ assay is a simple, efficient and rapid method that highly correlates with other biological tests (Botsford 2002). Trade-off between the specialized metabolism, and the primary metabolism dedicated to essential biochemical processes such as growth and reproduction can be assessed by this approach (Ivanisevic et al. 2011b). Bioactivities of extracts can be directly correlated to the expression level of targeted metabolites (Cachet et al. 2015; Martí et al. 2003; Reverter et al. 2016), and metabotypes were shown to explain bioactivity patterns (Ivanisevic et al. 2011b). However, metabolomics doesn't match necessarily bioactivity assessment. Indeed, metabolomics provides an overall picture of chemical complexity of a biological matrix, this picture being dependent of the selected technique (MS or NMR), but in any case without any indication of putative synergetic or antagonistic effects of the detected compounds. On the other hand, an assay such as the Microtox ${ }^{\circledR}$ integrates all putative synergetic or antagonistic effects of the extracted compounds, but the obtained value is only a proxy depending on the specificity of the model bacterial strain response.

The first objective of our study was to assess macroalgal investment in defensive traits using two non-equivalent approaches, UHPLC-HRMS metabolic fingerprinting and biogeographic variations of macroalgal bioactivities assessed with the Microtox ${ }^{\circledR}$ assay. The second objective was to understand how environmental factors (temperature, light) may influence macroalgal defensive traits. Finally, we also have evaluated the relationship between bioactivities 
and the status of the macroalga, its origin (introduced vs. native) and its cover together as an indicator of invasiveness, in order to relate the involvement of macroalgal chemical defenses in its proliferation trait.

\section{Methods}

\subsection{Biological Material}

Among the six different lineages of A. taxiformis (Delile) Trevisan de Saint-Léon (Rhodophyta, Bonnemaisoniaceae) (Andreakis et al. 2007, 2016; Dijoux et al. 2014), only five were considered in this study. This alga can cover hard and soft substrate from 0 to $45 \mathrm{~m}$ depth both in temperate and tropical waters. Asparagopsis armata (Harvey), a species distributed worldwide and currently composed of two distinct genetic clades (Dijoux et al. 2014), was also considered in this study. Only one lineage mostly growing on hard substrates at shallow depth was investigated. The genus is dioecious. Gametophytes stages present distinct male and female individuals, which alternates with a heteromorphic tetrasporophyte "Falkenbergia stage". In this study, we focused on the gametophyte stage of the macroalgae.

\subsection{Sampling}

A total of 289 individuals of A. taxiformis gametophytic stage were collected in 21 stations selected in 10 sites from two zones (temperate and tropical), from October 2012 to April 2015 (Table 1). Sampled stations presented highly variable A. taxiformis covers. Three classes of Asparagopsis cover were determined by visual assessment: low, 0-35\%, medium, 35-65\%, high 65-100\%. Asparagopsis armata was sampled in South of Spain where it lives in sympatry with A. taxiformis. Two temporal samplings of A. taxiformis were performed in Réunion (Saint Leu, four dates from October 2012 to July 2013) and in France (La Ciotat, six dates from November 2013 to April 2015).

\subsection{Metabolite extraction}

After collection, samples were transported in a cooler, stored at $-20^{\circ} \mathrm{C}$ before freeze-drying. Dried samples were preserved in silica gel and sent to Marseille (France). Each sample was then individually ground into a fine powder using a blender (Retsch ${ }^{\circledR}$ MM400, $30 \mathrm{~Hz}$ during $30 \mathrm{~s}$ ). One hundred milligram of each sample were extracted 3 times with $2 \mathrm{~mL}$ of $\mathrm{MeOH} / \mathrm{CH}_{2} \mathrm{Cl}_{2} 1: 1(\mathrm{v} / \mathrm{v})$ in an ultrasonic bath $(1 \mathrm{~min})$ at room temperature. The filtrates (PTFE, $0.22 \mu \mathrm{m}$, Restek®) were pooled and concentrated to dryness, adsorbing extracts on $\mathrm{C} 18$ silica particles (100 mg, non-end-capped C18 Polygoprep 60-50,
Macherey-Nagel $($ ). The extracts were then subjected to SPE (Strata C18-E, $500 \mathrm{mg}, 6 \mathrm{~mL}$, Phenomenex ${ }^{\circledR}$ ) eluting with $\mathrm{H}_{2} \mathrm{O}, \mathrm{MeOH}$, and $\mathrm{CH}_{2} \mathrm{Cl}_{2}(5 \mathrm{~mL}$ of each) after cartridge cleaning $(10 \mathrm{~mL} \mathrm{MeOH})$ and conditioning $(10 \mathrm{~mL}$ $\mathrm{H}_{2} \mathrm{O}$ ). $\mathrm{MeOH}$ fractions were evaporated to dryness, resuspended in $2 \mathrm{~mL}$ of $\mathrm{MeOH}$ prior to metabolomic analyses by UHPLC-QqTOF. After this first analysis, the same macroalgal extracts were concentrated to dryness ready to be used for bioactivity assessment using the Microtox® assay.

\subsection{Metabolomic analyses}

\subsubsection{Chemicals}

Methanol, dichloromethane and acetonitrile of analytical quality were purchased from Sigma-Aldrich (Chromasolv ${ }^{\circledR}$, gradient grade). Formic acid and ammonium formate (LC-MS additives, Ultra grade) were provided by Fluka.

\subsubsection{LC-MS analyses}

Analyses were performed on an UHPLC-QqToF instrument: UHPLC is equipped with RS Pump, autosampler and thermostated column compartment and UV diode array (Dionex Ultimate 3000, Thermo Scientific ${ }^{\circledR}$ ) and coupled to a high resolution mass spectrometer (MS) equipped with an ESI source (Impact II, Bruker Daltonicsß). Mass spectra were acquired in positive and negative mode consecutively. Elution rate was set to $0.5 \mathrm{~mL} \mathrm{~min}^{-1}$ at a constant temperature of $40^{\circ} \mathrm{C}$. Injection volume was set to $10 \mu \mathrm{L}$. Chromatographic solvents were composed of A: water with $0.1 \%$ formic acid (positive mode), or $10 \mathrm{mM}$ ammonium formate (negative mode), and B: acetonitrile/water (95:5) with the same respective additives. UHPLC separation occurs on an Acclaim RSLC C18 column $(2.1 \times 100 \mathrm{~mm}, 2.2 \mu \mathrm{m}$, Thermo Scientific () . According to the study of spatial and temporal patterns, chromatographic elution gradients were adjusted to improve peak resolution using a pooled sample. Two chromatographic elution gradients were thus applied. For the study of spatial patterns, the program was set up at $40 \%$ B during $2 \mathrm{~min}$, followed by a linear gradient up to $100 \% \mathrm{~B}$ during $8 \mathrm{~min}$, then maintained $4 \mathrm{~min}$ in isocratic mode. The analysis was followed by a return to initial conditions for column equilibration during $3 \mathrm{~min}$ for a total runtime of $17 \mathrm{~min}$. For the study of temporal patterns, the program was set up at $2 \% \mathrm{~B}$ during $1 \mathrm{~min}$, followed by a linear gradient up to $80 \%$ B during $5 \mathrm{~min}$, then maintained $6 \mathrm{~min}$ in isocratic mode at $80 \% \mathrm{~B}$. The analysis was followed by a phase of $100 \% \mathrm{~B}$ during $4 \mathrm{~min}$ and equilibration during $4 \mathrm{~min}$ for a total runtime of $20 \mathrm{~min}$. Analyses were processed in separate batches for the study of spatial and temporal variation of the metabotypes. Macroalgal extracts 


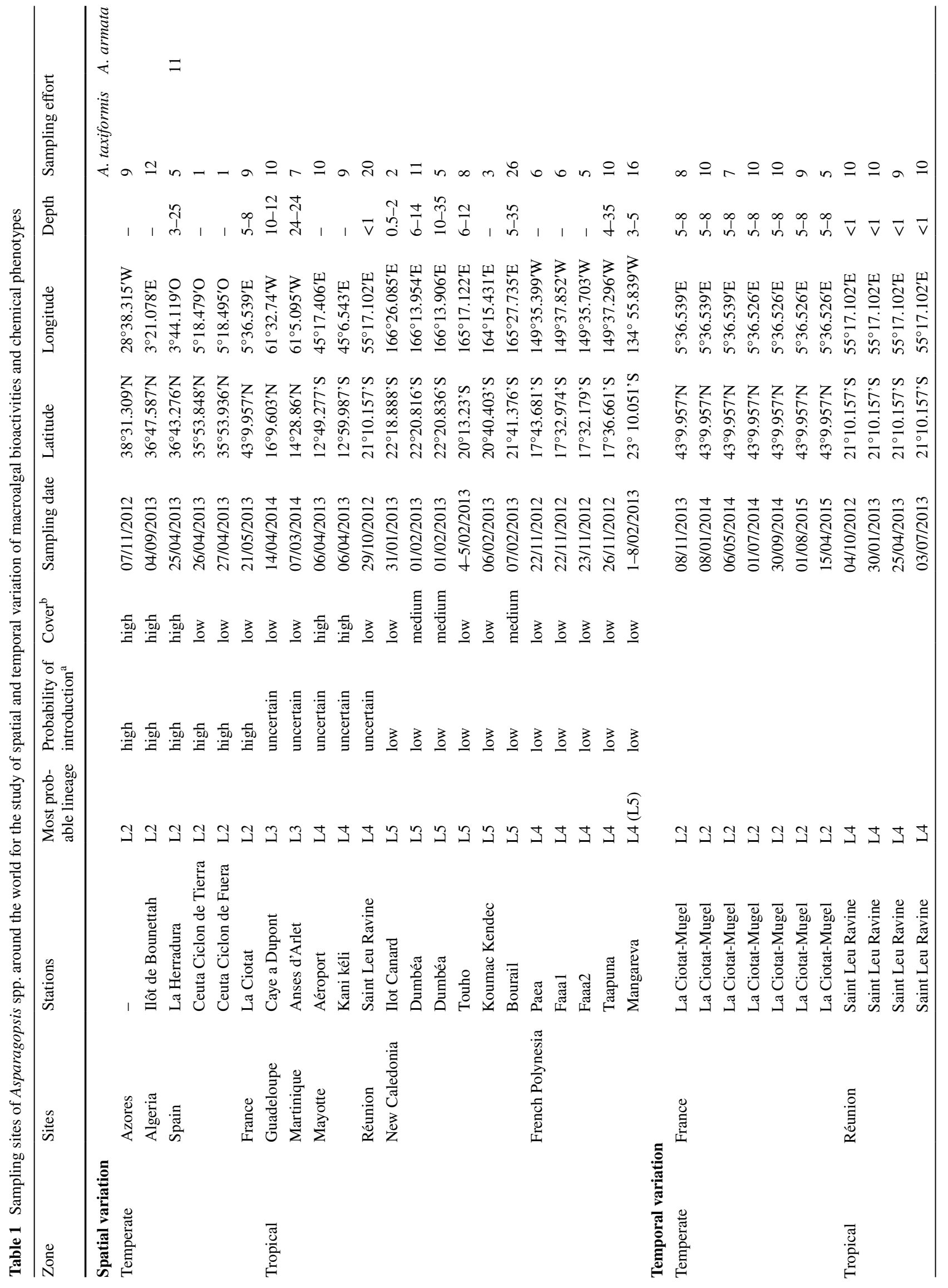


were randomly injected according to sampling sites or dates, alternating the pooled sample injected every 6 samples to realize inter and intra-batch calibration due to MS shift over time.

MS parameters were set as follows for positive mode (and negative mode): nebulizer gas, $\mathrm{N}_{2}$ at $31 \mathrm{psi}$ (51 psi), dry gas $\mathrm{N}_{2}$ at $8 \mathrm{~L} \mathrm{~min}^{-1}\left(12 \mathrm{~L} \mathrm{~min}^{-1}\right)$, capillary temperature at $200{ }^{\circ} \mathrm{C}$ and voltage at $2500 \mathrm{~V}(3000 \mathrm{~V})$. Data were acquired at $2 \mathrm{~Hz}$ in full scan mode from 50 to $1200 \mathrm{amu}$. Mass spectrometer was systematically calibrated with formate/acetate solution forming clusters on the studied mass range before a full set of analysis. The same calibration solution was automatically injected before each sample for internal mass calibration. Data-dependent acquisition $\mathrm{MS}^{2}$ experiments were also conducted (renewed every three major precursors) on some samples of each location.

\subsubsection{Data analyses}

Constructor raw analyses were automatically calibrated using internal calibrant, before exporting data in netCDF files (centroid mode) using Bruker Compass DataAnalysis 4.3. All converted analysis were then processed by XCMS software (Smith et al. 2006) under R (R_Core_Team 2013), using the different steps necessary to generate the final data matrix: (1) Peak picking (peakwidth $=\mathrm{c}(2,20), \mathrm{ppm}=2$ ) without threshold prefilter (Patti et al. 2012), (2) retention time correction (method = "obiwarp"), (3) grouping $(\mathrm{bw}=10, \operatorname{minfrac}=0.3$, minsamp $=1)$, (4) Fillpeaks, and finally (5) report and data matrix generation transferred to Excel. Each individual ion was finally normalized (if necessary according to the drift of equivalent ion of pooled samples) and injection order (van der Kloet et al. 2009). Data were calibrated between batches (inter-batch calibration for the study of spatial patterns) by dividing each ion by the intra-batch mean value of pooled-sample ions, and multiplying by the total mean value for all batches (Ejigu et al. 2013). Metabolites were annotated with constructor software (Bruker Compass DataAnalysis 4.3).

\subsection{Bioactivity assays}

Bioactivities of macroalgal extracts were assessed using the standardized Microtox ${ }^{\circledR}$ assay (Microbics, USA). This ecotoxicological method measures the effect of compounds on the respiratory metabolism of Allivibrio fischeri which is correlated to the intensity of its natural bioluminescence (Johnson 2005). Extracts were initially prepared at $2 \mathrm{mg} \mathrm{mL}^{-1}$ in artificial seawater with $2 \%$ of acetone to facilitate dissolution, and then diluted (twofold) three times in order to test their effect on bacteria and to draw $\mathrm{EC}_{50}$ curves. $\mathrm{EC}_{50}$ expressed in $\mu \mathrm{g} \mathrm{mL}-1$ represents the 
concentration that decreases half of the initial luminescence after $5 \mathrm{~min}$ of exposure to extracts.

\subsection{Environmental factors}

Sea surface temperature (SST in ${ }^{\circ} \mathrm{C}$ ) and Photosynthetically available radiation (PAR in mol m $\mathrm{m}^{-2} \mathrm{day}^{-1}$ ) were obtained from NASA GES DISC for all sites (http://giovanni.gsfc.nasa.gov). In France, supplementary abiotic factors related to water chemistry such as ammonium $\left(\mathrm{NH}_{4}{ }^{+}\right)$, nitrate $\left(\mathrm{NO}_{3}^{-}\right)$, and phosphate $\left(\mathrm{PO}_{4}{ }^{3-}\right)$ concentrations

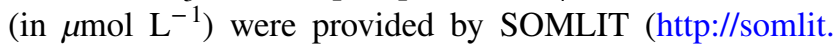
epoc.u-bordeaux1.fr/fr//.

\subsection{Statistical analyses}

Principal components analysis (PCA) were realized using the "ade4 package" (Dray and Dufour 2007). PCA were centered (the mean ion intensity of all samples was subtracted to each sample ion intensity) and normalized (consequently divided by the relative standard deviation of ion intensity of all samples). PERMANOVA (adonis function, $1 \mathrm{e}^{5}$ permutations) and ANalysis OF SIMilarity (ANOSIM function using Euclidean distances) were performed with the "vegan package" (Oksanen et al. 2015). PLSDA were realized using the "RVAideMemoire package" (Hervé 2016) on scaled raw data according to zones and unscaled log-transformed data according to sites. Permutational test based on cross model validation procedures (MVA.test and pairwise.MVA.test) were used to test differences between groups: outer loop fivefold cross-validation, inner loop fourfold cross-validation according to zones and sites (Szymanska et al. 2012). Very important peaks (VIPs) were determined according to the PLS-DA loading plots. Non-parametric analysis (Kruskal-Wallis test followed by Steel-Dwass-Critchlow-Fligner post-hoc test, and Mann-Whitney) were performed on XLSTAT version 2015.4.01.20575 to test differences of macroalgal bioactivities according to zones and sites. The relationships of macroalgal bioactivities against $A$. taxiformis cover, latitudes or environmental factors were assessed using Spearman's correlations rank test (Rs) using XLSTAT.

\section{Results}

\subsection{Spatial variation of the macroalgal chemical profiles and bioactivities}

All the macroalgal metabotypes were plotted on principal component analysis (PCA) taking into account 2683 negative and 2182 positive ions. The PCA shows that the global inertia remains low with $11.9 \%$ of explanation of the variability (Fig. 1). Variances on axis $1-3$ and $2-3$ of the PCA show similar values with $11.2 \%$ and $9.3 \%$, respectively. But the divergence between groups (zones and sites) is more evident along the $2-3$ axis. Whereas the difference between macroalgal metabotypes in tropical and temperate zones is not statistically supported (PERMANOVA, $\mathrm{F}=2.7, \mathrm{p}=0.064)$, a significant difference between sites is recorded (PERMANOVA, $\mathrm{F}=2.9, \mathrm{p}=0.003$ ), with a weak Pearson correlation factor $\left(\mathrm{R}^{2}=0.13\right)$. A similarity test between sites confirmed that macroalgae sampled in Azores and France are significantly different from all other sites, as well as for macroalgae sampled in Martinique and New Caledonia (ANOSIM, R $=0.281, \mathrm{p}<0.001$ ) (Fig $\mathrm{S} 1$ and Table S1 in Supporting Information). Eight metabolite features were selected as chemomarkers with regards to the congruence of ions detected in both negative and positive modes from the PPLS-DA loading plots. They partly explain the dispersion of groups that differentiate temperate metabotypes from tropical ones (PPLS-DA, NMC $=2.5 \%$, $\mathrm{p}=0.001$ ) (Fig S2). Differentiation of groups was also effective for metabotypes of algae sampled from the different sites (PPLS-DA, NMC $=31.8 \%, \mathrm{p}=0.001)($ Fig S3 and Table S2). Most probable raw formula of biomarkers did not match with any known compounds from the genus Asparagopsis (Table S3).

Macroalgal bioactivities are negatively correlated with latitudes ( $\mathrm{Rs}=-0.148, \mathrm{R}^{2}=0.02, \mathrm{p}=0.041$ ). Overall A. taxiformis from temperate zones show higher bioactivities $\left(\mathrm{EC}_{50}=32 \pm 3 \mu \mathrm{g} \mathrm{mL} \mathrm{m}^{-1}\right.$, mean $\left.\pm \mathrm{SE}\right)$ than those

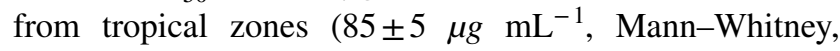
$\mathrm{U}=4256, \mathrm{p}<0.001$, Figs. 2, 3a). Macroalgal bioactivities also differ significantly according to sampling sites (Kruskal-Wallis, $\mathrm{K}=90, \mathrm{p}<0.001$, Fig. $2 b$ ). $\mathrm{EC}_{50}$ ranged from $20 \pm 4 \mu \mathrm{g} \mathrm{mL} L^{-1}$ (Azores) to $117 \pm 15 \mu \mathrm{g} \mathrm{mL}^{-1}$ (French Polynesia). Similarly to macroalgal bioactivities found in Azores, high values were recorded in France $\left(31 \pm 4 \mu g \mathrm{~mL}^{-1}\right)$, Algeria $\left(33 \pm 5 \mu g \mathrm{~mL}^{-1}\right)$ and Spain $\left(52 \pm 13 \mu \mathrm{g} \mathrm{mL} \mathrm{m}^{-1}\right)$. In comparison, A. armata sampled in South of Spain did not show significant different $\mathrm{EC}_{50}$ values from A. taxiformis sampled in France, Algeria and

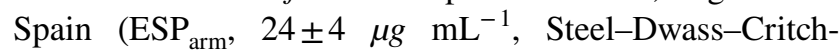
low-Fligner post hoc test, $\mathrm{p}>0.05$ ).

Macroalgae from Martinique $\left(114 \pm 24 \mu \mathrm{gL}^{-1}\right)$ and French Polynesia $\left(117 \pm 15 \mu \mathrm{g} \mathrm{mL}{ }^{-1}\right)$ showed the lowest bioactivities, whereas macroalgae from Mayotte showed the highest values among the tropical macroalgae $(57 \pm 8 \mu \mathrm{g}$ $\left.\mathrm{mL}^{-1}\right)$. Asparagopsis taxiformis from other tropical sites (New Caledonia, Réunion and Guadeloupe) exhibited intermediate bioactivities (respectively $72 \pm 7 \mu \mathrm{g} \mathrm{mL} \mathrm{m}^{-1}$,

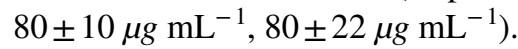

No relationship between the spatial pattern of variability in the macroalgal bioactivity and the macroalgal cover has been established $\left(\mathrm{Rs}=0.061, \mathrm{R}^{2}=0.004, \mathrm{p}=0.336\right.$ ). 

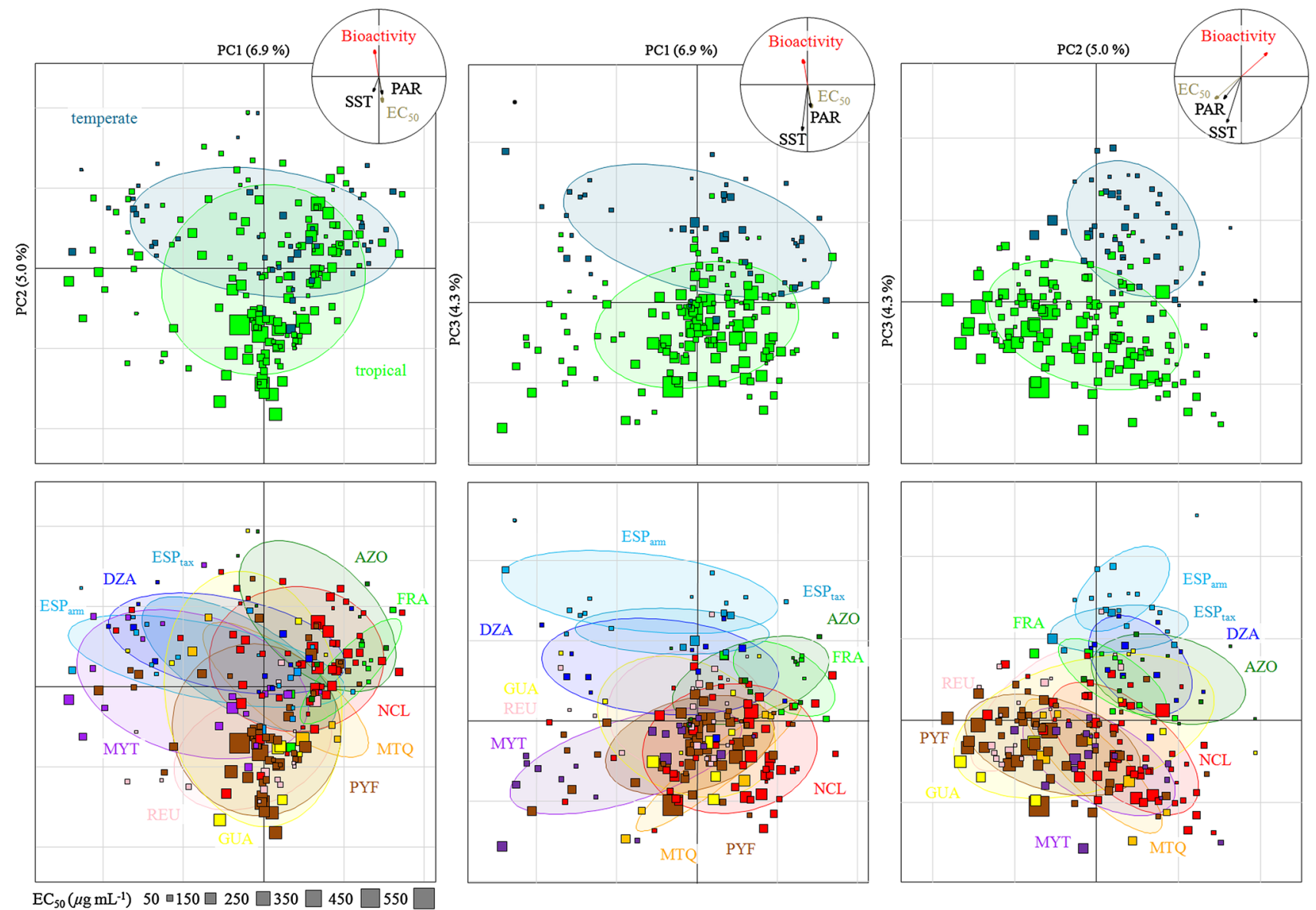

Fig. 1 Principal component analysis (PCA) of methanolic macroalgal extracts analyzed in UHPLC-QqToF (positive and negative modes) according to zones (temperate versus tropical) and sites PYF: French Polynesia, MTQ: Martinique, GUA: Guadeloupe, MYT: Mayotte, REU: Réunion, NCL: New Caledonia, AZO: Azores, FRA: France, DZA: Algeria; ESP: Spain with A. taxiformis, ESP ${ }_{\text {tax }}$ and

This spatial pattern in macroalgal bioactivities is actually negatively correlated with SST $\left(\mathrm{Rs}=-0.428, \mathrm{R}^{2}=0.18\right.$, $\mathrm{p}<0.001)$ and PAR ( $\mathrm{Rs}=-0.37, \mathrm{R}^{2}=0.14, \mathrm{p}<0.001$ ) which explain respectively 18 and $14 \%$ of the overall variability (Fig. 1; Table 2).

\subsection{Temporal variation of the macroalgal chemical profiles and bioactivities}

Macroalgae from France and Réunion displayed distinct metabotypes that varied in time, with overall a much higher variability recorded in Réunion and no clear pattern of seasonal variation in France (Fig. 3a, b). PCAs show that inertia are globally higher when assessing the spatial variability, with about 19\% explained in France and 24\% in Réunion. Although we were able to distinguish several metabotypes in these time series, no clear chemomarkers
A. armata $\mathrm{ESP}_{\mathrm{arm}}$. Maximal variance on axis 1-2 represents $11.9 \%$. Variances on axis $1-3$ and 2-3 represent 11.2 and $9.3 \%$. $\mathrm{EC}_{50}$ (in $\mu \mathrm{g} \mathrm{mL} \mathrm{m}^{-1}$ ), opposite to macroalgal bioactivity, are represented with increasing squares. Environmental factors on loadings are figured in black (Sea Surface Temperature, PAR: Photosynthetically Active Radiation) (see Table S4 for details according to sites)

were identified to explain this variability. This divergence likely relies on several minor ions.

The $\mathrm{EC}_{50}$ values for $A$. taxiformis from France range from $13 \pm 3$ to $37 \pm 5 \mu g \mathrm{~mL}^{-1}$ (mean $\pm \mathrm{SE}$ ) revealing a high bioactivity all along the year (Fig. 4a), individuals sampled in January 2015 exhibiting the lowest bioactivity values recorded for this site $\left(\mathrm{EC}_{50}=37 \pm 5 \mu \mathrm{g} \mathrm{m} \mathrm{m}^{-1}\right)$. This temporal pattern of variability is positively correlated to SST variations $\left(\mathrm{Rs}=0.287, \mathrm{R}^{2}=0.08, \mathrm{p}=0.02\right.$ ) (PAR, $\mathrm{p}>0.05$ ), and negatively correlated to variation in ammonium and nitrate concentrations $\left(\mathrm{Rs}=-0.373, \mathrm{R}^{2}=0.14\right.$, $\mathrm{p}=0.003$ for $\mathrm{NH}_{4}{ }^{+} ; \mathrm{Rs}=-0.435, \mathrm{R}^{2}=0.19, \mathrm{p}<0.001$ for $\mathrm{NO}_{3}^{-}$; Table 2).

In Réunion, macroalgal bioactivities show a higher variability than those recorded for temperate site (Kruskal-Wallis, $\mathrm{K}=29, \mathrm{p}<0.001$; Fig. 4b). The lowest

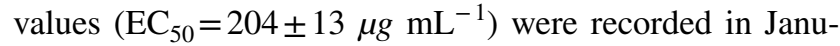
ary when the seawater temperature is the highest (monthly 

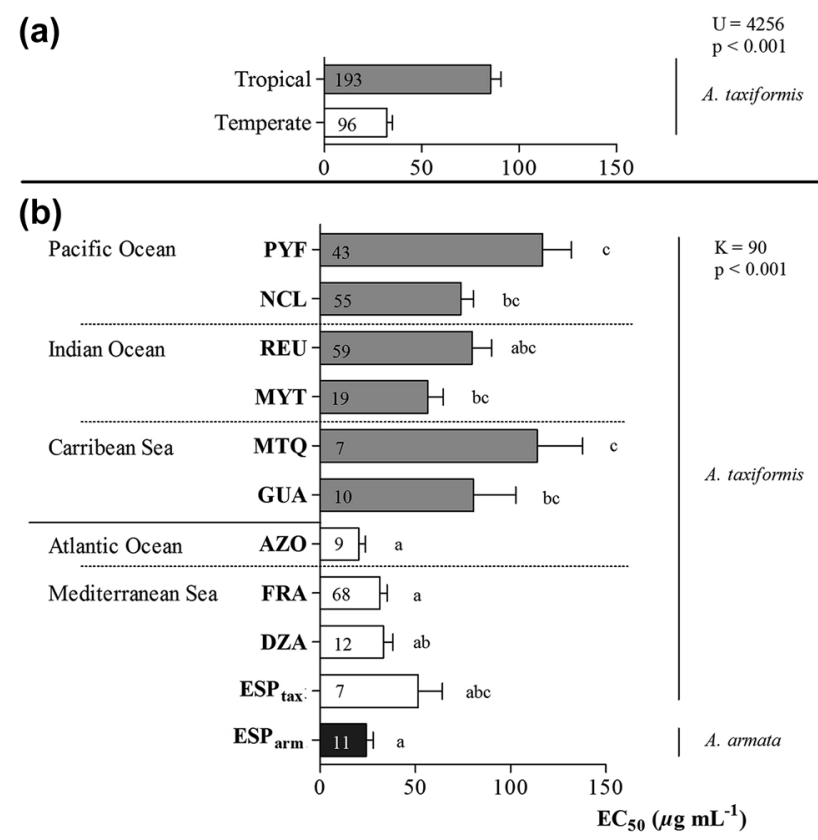

Fig. 2 Mean bioactivities $( \pm$ SE) of methanolic macroalgal extracts measured with Microtox ${ }^{\circledR}$ ecotoxicological assay according to (a) sampling zones: tropical vs. temperate and (b) sites: PYF: French Polynesia, NCL: New Caledonia, REU: Réunion, MYT: Mayotte, MTQ: Martinique, GUA: Guadeloupe, AZO: Azores, FRA, France, DZA: Algeria, ESP: Spain. Numbers of samples tested written in bars. Comparisons between zones were achieved with Mann-Whitney test. Comparisons between sites were achieved with KruskalWallis test followed by Steel-Dwass-Critchlow-Fligner post hoc test. Letters figure differences between groups

mean SST of $27.1^{\circ} \mathrm{C}$, Table S5), whereas the highest values $\left(\mathrm{EC}_{50}=14 \pm 3 \mu \mathrm{g} \mathrm{mL}^{-1}\right)$ were recorded in July when the seawater temperature is lower (monthly mean SST of $23.5^{\circ} \mathrm{C}$ ). There is thus a negative correlation between the macroalgal bioactivity, the SST and the PAR variability $\left(\mathrm{Rs}=-0.729, \mathrm{R}^{2}=0.53, \mathrm{p}<0.001\right.$ and $\mathrm{Rs}=-0.532$, $\mathrm{R}^{2}=0.28, \mathrm{p}<0.001$, for SST and PAR respectively).

\section{Discussion}

\subsection{Applying LC-MS-based metabolomics to halogenated metabolites}

The genus Asparagopsis is known to biosynthesize about one hundred of halogenated volatile organic compounds (Kladi et al. 2004). Whereas the major metabolites are assumed to be low molecular weight brominated compounds (Paul et al. 2006a), the metabolomic approach used in this study mostly detected non-halogenated metabolites. This might be explained by the volatility of these small compounds that are mainly detected using GC-MS analysis. Higher molecular weight metabolites with six carbons named mahorones were reported from this species (Greff et al. 2014). Targeted search of the mahorones in collected gametophytes revealed the presence of 5-bromomahorone in almost all samples without any clear pattern of distribution between samples. The second mahorone was not detected maybe because of difficulties in the ionization process of these molecules as described by Greff et al. (2014). In this study, brominated and iodinated metabolites, were only evidenced by the release of bromide and iodide in the negative mode. Electrospray ionization is strongly dependent of metabolite physical and chemical properties. In negative mode, the detection of halogenated metabolites are not favored as the electrons may be trapped by halogens, rendering halogenated metabolites unstable and undetectable to mass spectrometer (except for halide ions). A metabolomic approach using HRMS is thus suitable for the detection of easily ionizable metabolites present in the macroalgae, but there is a limitation when the major specialized metabolites are highly halogenated.

\subsection{Relationship between metabotypes and bioactivities}

Although, various metabotypes were clearly discriminated, the divergence is due to a high number of minor ions. In this study, phenotypes of temperate macroalgae, especially A. armata sampled in Spain and A. taxiformis sampled in Spain and Algeria, distinguish mostly by the presence of some metabolite features named MF1-MF8 not previously described for these species. Macroalgae sampled in temperate environments evidenced higher bioactivities than those sampled under tropical environments indicating that macroalgal investment in defense was greater under higher latitudes. So far, temperate A. taxiformis (France, Azores, Spain and Algeria) is mainly represented by the introduced lineage 2 (L2) (Andreakis et al. 2007; Dijoux et al. 2014) suggesting that this NIS can modify its investment in chemical traits. Both species, A. taxiformis and A. armata, sampled in South Spain showed closer phenotypes and bioactivities than A. taxiformis sampled at a larger geographic scale. This outcome suggests that macroalgal phenotypes are more driven by environmental factors, at least partly related to microbial communities, than to genetic factors. This phenotypic variability related to the exposome was already known at the morphological level, as a given genetic lineage or population can include various morphotypes (Dijoux 2014; Monro and Poore 2009), and the morphotype variability could never be explained by genetics (Dijoux 2014). Although MS metabolomics was applied with success to a rather good number of chemotaxonomy or chemosystematics works, this study did not allow to discriminate macroalgal lineages. The unusual ionization processes of the major and highly halogenated specialized metabolites produced by these species might be one 


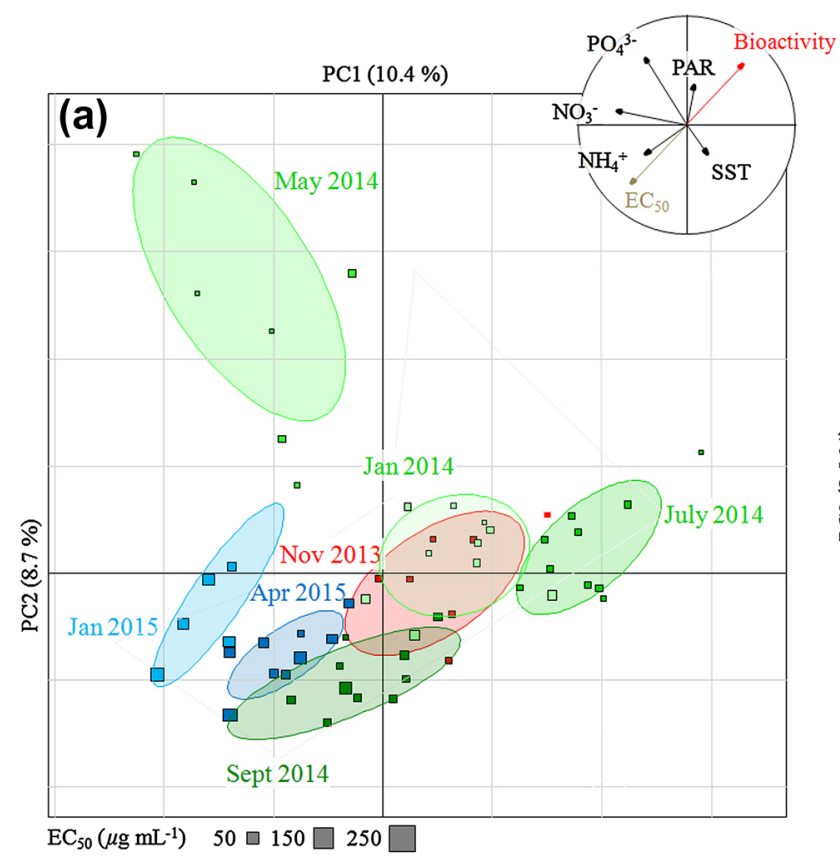

Fig. 3 Principal component analysis (PCA) of methanolic macroalgal extracts analyzed in UHPLC-QqToF according to temporal variation for two sites/zones: (a) France for temperate zone and (b) Réunion for tropical zone. $\mathrm{EC}_{50}$ (in $\mu \mathrm{g} \mathrm{mL}^{-1}$ ) of A. taxiformis opposite to

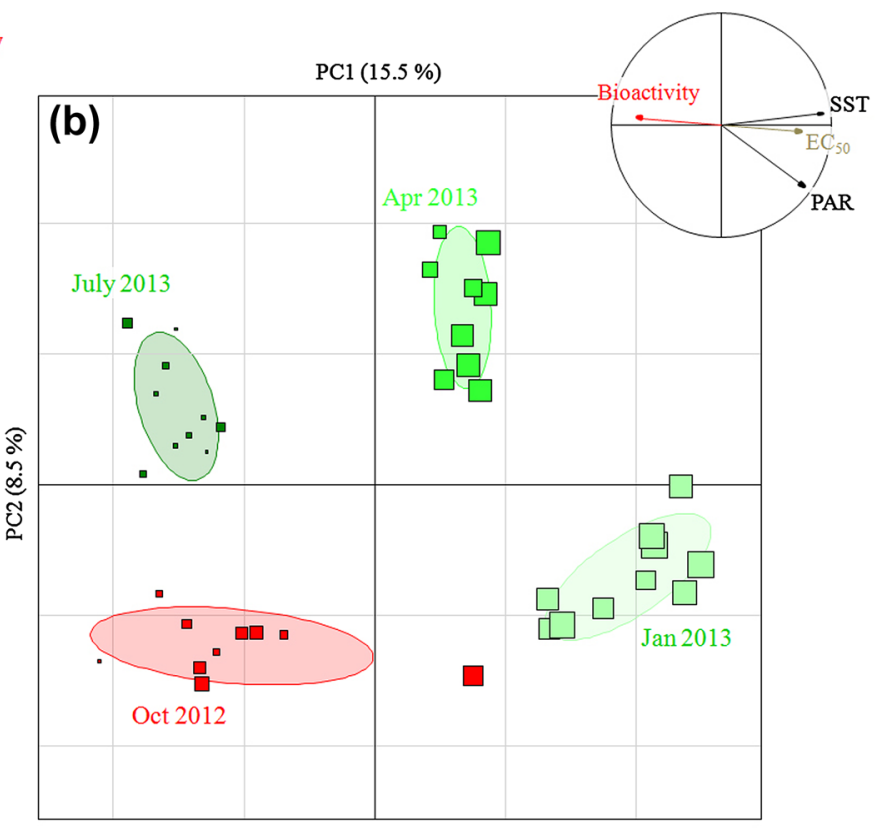

macroalgal bioactivities, are figured with increasing squares. Loadings are figured in black for factors (SST: sea surface temperature, PAR: photosynthetically active radiation, $\mathrm{NH}_{4}^{+}$: ammonium concentration, $\mathrm{NO}_{3}{ }^{-}$: nitrate concentration, $\mathrm{PO}_{4}{ }^{3-}$ : phosphate concentration)
Table 2 Spearman's matrix of correlations between dependant (bioactivity) and independent variables (SST: sea surface temperature, PAR: photosynthetically active radiation, $\mathrm{NH}_{4}^{+}$: ammonium concentration, $\mathrm{NO}_{3}{ }^{-}$: nitrate concentration, $\mathrm{PO}_{4}{ }^{3-}$ : phosphate concentration)

\begin{tabular}{|c|c|c|c|c|c|c|c|}
\hline Pattern & Sites & Variables & Bioactivity & SST & PAR & $\mathrm{NH}_{4}^{+}$ & $\mathrm{NO}_{3}^{-}$ \\
\hline \multirow[t]{2}{*}{ Spatial } & & SST & $-0.428(0.18)$ & & & & \\
\hline & & PAR & $-0.370(0.14)$ & 0.377 & & & \\
\hline \multirow[t]{7}{*}{ Temporal } & France & SST & $0.287(0.08)$ & & & & \\
\hline & & PAR & $0.175(0.03)$ & 0.661 & & & \\
\hline & & $\mathrm{NH}_{4}^{+}$ & $-0.373(0.14)$ & -0.617 & -0.622 & & \\
\hline & & $\mathrm{NO}_{3}^{-}$ & $-0.435(0.19)$ & -0.654 & -0.233 & 0.811 & \\
\hline & & $\mathrm{PO}_{4}^{3-}$ & $0.079(0.06)$ & -0.450 & -0.294 & 0.640 & 0.602 \\
\hline & Réunion & SST & $-0.729(0.53)$ & & & & \\
\hline & & PAR & $-0.532(0.28)$ & 0.913 & & & \\
\hline
\end{tabular}

Bold numbers show significant value at the level $\alpha \leq 0.05$. Coefficient of determination (Spearman $\mathrm{R}^{2}$ ) are into brackets of the main explanation, calling thus to use other technical approaches. Besides metabolomics, bioactivity assessment using the Microtox ${ }^{\circledR}$ assay appeared as a relevant complement to our MS approach in order to detect putative shift in macroalgal chemical diversity and its related bioactivity.

In addition, the results of the Microtox ${ }^{\circledR}$ analyses, used as a proxy of the production of chemical defenses, are not in accordance with the Latitudinal Gradient Hypothesis (LGH) used on land where plants allocate more in defensive traits under lower latitudes. It also shows that environmental factors are driving-forces that can strongly influence the specialized metabolism and its related bioactivity or putative ecological function (Pelletreau and Targett 2008; Puglisi et al. 2014; Putz and Proksch 2010). A higher herbivory pressure in tropical ecosystems than in temperate ones can rely on the species richness and biomass of tropical ecosystems (Brown 2014; GonzálezBergonzoni et al. 2012), but also to a stronger resistance of herbivores to plant metabolites (Craft et al. 2013). Previous study conducted with $A$. armata demonstrated that an increase in toxicity towards bacteria was related to the amount of bioactive halogenated compounds (Paul et al. 2006a). The halogenation process was also shown determinant for the deterrence of non-specialized herbivores (Paul 
Fig. 4 Mean bioactivities $( \pm$ SE) of methanolic macroalgal extracts measured with Microtox ${ }^{\circledR}$ assay according to season at (a) La Ciotat (France) and (b) Saint Leu (Réunion). Numbers of samples tested are written in bars. Comparisons were achieved using KruskalWallis test followed by SteelDwass-Critchlow-Fligner post hoc test. Letters figure differences between groups
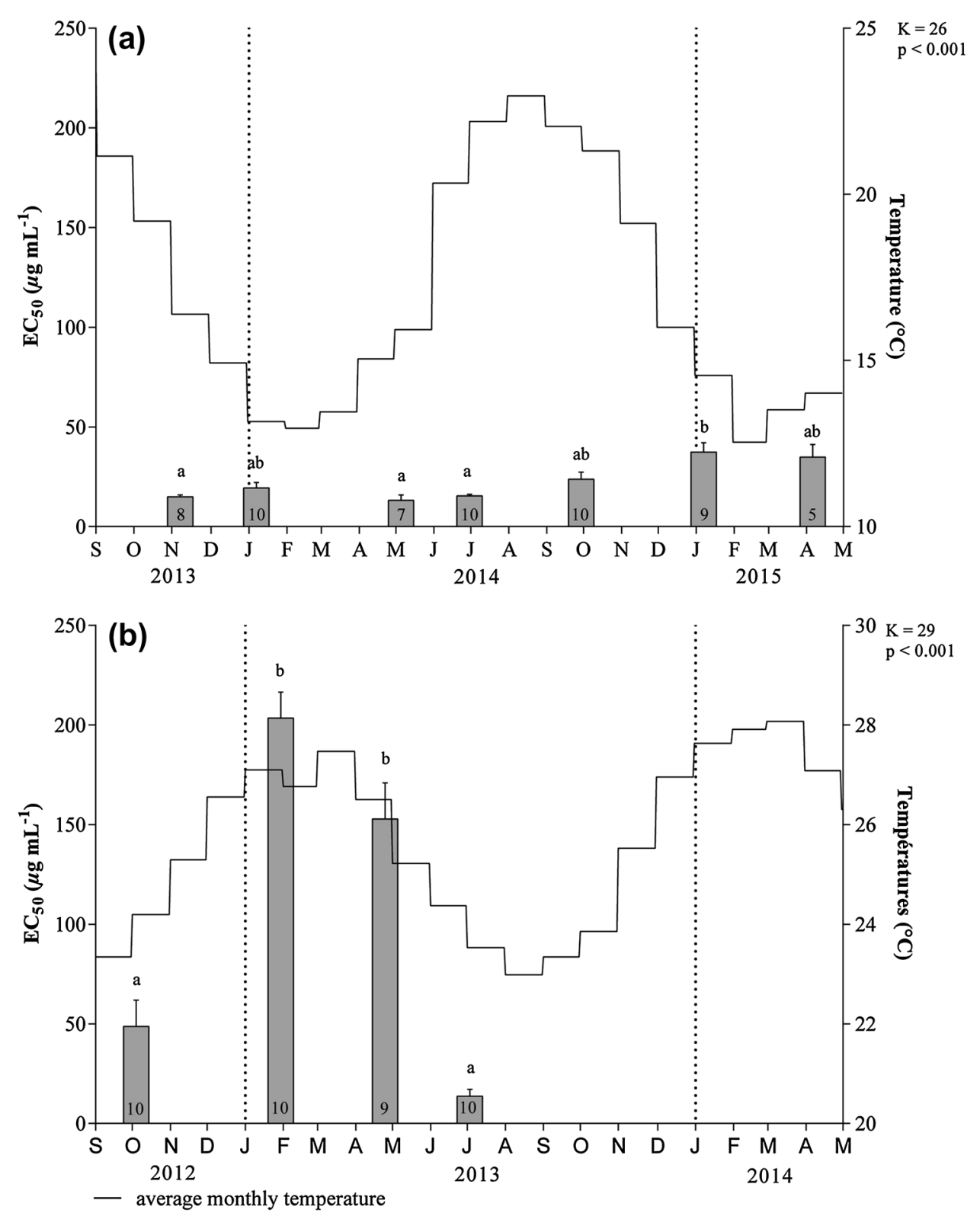

et al. 2006b). However, only few grazers are recognized to feed on Asparagopsis: the sea hare Aplysia parvula (Paul et al. 2006b; Rogers et al. 2003; Vergés et al. 2008) and the abalone Haliotis rubra (Paul et al. 2006b; Shepherd and Steinberg 1992 in Paul 2006) are known to graze $A$. armata, and only the sea hare Aplysia fasciata was reported to feed on A. taxiformis (Altamirano et al. 2008).

Competition for space might also promote defensive traits as macroalgae can be abundant in temperate infralittoral zones (Mineur et al. 2015; Vermeij 1978). For A. taxiformis in the Mediterranean Sea, the pressure of competition might be expected to be rather high in spring when productivity is the highest (Pinedo et al. 2015), but our temporal survey showed rather similar bioactivities all along the year. If macroalgal-macroalgal interactions can induce defensive metabolites biosynthesis, it remains however difficult to explain why A. taxiformis maintains such a high level of defensive traits whereas these interactions are supposed to decrease. Competition is closely related to light availability. Under temperate latitudes, the photophilic community is generally more bioactive than the hemisciaphilic communities indicating that light plays a key role in bioactivity and the biosynthesis of defense related metabolites (Martí et al. 2004; Mtolera et al. 1996). Paul (2006) demonstrated that the production of specialized metabolites was not costly for A. armata when the light is not limited, as biosynthesis was positively correlated to growth. Yet, light is scarcely limited except when competition with fleshy macroalgae reaches a maximum. Under tropics, high irradiance should lead to the synthesis 
of defense metabolites as revealed for the Rhodophyta Eucheuma denticulatum (Mtolera et al. 1996), but excessive irradiance may also stress macroalgae leading to biosynthesis switch (Cronin and Hay 1996).

Taking all these factors together, seasonal bioactivity variation can give some clues. Surprisingly, the highest variation of macroalgal bioactivities was displayed by A. taxiformis in tropical region (Réunion) while seasonality was quite weak with a lower temperature range $\left(5^{\circ} \mathrm{C}\right)$ and high irradiance all along the year. During austral winter (with SST of $23-24^{\circ} \mathrm{C}$ ), A. taxiformis from Réunion showed bioactivities equivalent to temperate zones whereas the lowest bioactivities were displayed in austral summer when the water temperature was higher $\left(26-27^{\circ} \mathrm{C}\right)$. Asparagopsis taxiformis thermal tolerance was tested up to $30^{\circ} \mathrm{C}$ (Padilla-Gamino and Carpenter 2007). However, high temperatures coupled to high irradiance and low nutrient levels that characterize tropical environments (Vermeij 1978) may lead to metabolic alterations as suggested by Cronin and Hay (1996). Thus, a way to explain the higher defensive traits in temperate environments is to consider that maintaining a high level of defensive trait may not be so costly as long as light and nutrients are available, and temperature physiologically adequate.

\subsection{Relationship between macroalgal bioactivities and invasiveness}

In temperate regions, $A$. taxiformis was reported to be recently introduced in many places. In Azores, A. taxiformis spread all around the islands until the last $90^{\prime}$ and it is now well established (Cardigos et al. 2006; Chainho et al. 2015; Micael et al. 2014). The last report on the worldwide distribution of $A$. taxiformis genetic lineages confirmed the presence of the introduced L2 in two Azorean Islands (Dijoux et al. 2014). In the Western Mediterranean Sea, only the L2 has been recorded so far (Andreakis et al. 2004, 2007, 2009; Dijoux et al. 2014), but an invasive trait is not recorded everywhere (Zenetos et al. 2012). In Alboran Sea, where this species has spread quickly since the late XXth century, A. taxiformis can form monospecific stands in several places along the Iberian coasts (Altamirano et al. 2008, 2010). In the same biogeographic region, a high cover of $A$. taxiformis was also recorded off the Algerian coast, while the macroalga is poorly distributed at Ceuta and the Strait of Gibraltar. Thus, for the widespread lineage 2 which is considered as invasive in some regions of the Mediterranean Sea and North Atlantic (Altamirano et al. 2008; Micael et al. 2014; Streftaris and Zenetos 2006), we observed highly variable fate in the indigenous benthic community, proliferating in some places and rather discreet in others. This observation can be extended to different lineages present in other geographic context, which tends to indicate no link between macroalgal bioactivities, their metabotypes and their invasiveness. It is likely that other physiological traits, compared to indigenous sessile organisms, may explain its success in certain habitats, such as special efficiencies for up-taking nutrients, for spreading a specific life cycle stage, or for resisting to environmental stress thanks to the polyploid status of the thalli.

\section{References}

Adams, J. M., Rehill, B., Zhang, Y., \& Gower, J. (2008). A test of the latitudinal defense hypothesis: Herbivory, tannins and total phenolics in four North American tree species. Ecological Research, 24, 697-704. doi:10.1007/s11284-008-0541-x.

Altamirano, M., de la Rosa, J., Zanolla, M., Souza-Egipsy, V., \& Diaz, J. (2010). New records for the benthic marine flora of Chafarinas Islands (Alboran Sea, Western Mediterranean). Acta Botanica Malacitana, 35, 165-167.

Altamirano, M., Muñoz, A. R., de la Rosa, J., Barrajón-Minguez, A., Barrajón-Domenech, A., Moreno-Robledo, C., et al. (2008). The invasive species Asparagopsis taxiformis (Bonnemaisoniales, Rhodophyta) on Andalusian coasts (Southern Spain): Reproductive stages, new records and invaded communities. Acta Botanica Malacitana, 33, 5-15.

Andreakis, N., Costello, P., Zanolla, M., Saunders, G. W., \& Mata, L. (2016). Endemic or introduced? Phylogeography of Asparagopsis (Florideophyceae) in Australia reveals multiple introductions and a new mitochondrial lineage. Journal of Phycology, 52, 141-147. doi:10.1111/jpy.12373.

Andreakis, N., Kooistra, W. H. C. F., \& Procaccini, G. (2009). High genetic diversity and connectivity in the polyploid invasive seaweed Asparagopsis taxiformis (Bonnemaisoniales) in the Mediterranean, explored with microsatellite alleles and multilocus genotypes. Molecular Ecology, 18, 212-226. doi:10.1111/j.1365-294X.2008.04022.x.

Andreakis, N., Procaccini, G., \& Kooistra, W. (2004). Asparagopsis taxiformis and Asparagopsis armata (Bonnemaisoniales, Rhodophyta): Genetic and morphological identification of Mediterranean populations. European Journal of Phycology, 39, 273-283. doi:10.1080/0967026042000236436.

Andreakis, N., Procaccini, G., Maggs, C., \& Kooistra, W. H. C. F. (2007). Phylogeography of the invasive seaweed Asparagopsis (Bonnemaisoniales, Rhodophyta) reveals cryptic diversity. Molecular Ecology, 16, 2285-2299. doi:10.1111/j.1365-294X.2007.03306.x.

Andrew, N. R., \& Hughes, L. (2005). Herbivore damage along a latitudinal gradient: relative impacts of different feeding guilds. Oikos, 108, 176-182. doi:10.1111/j.0030-1299.2005.13457.x.

Bolser, R. C., \& Hay, M. E. (1996). Are tropical plants better defended? Palatability and defenses of temperate vs. tropical seaweeds. Ecology, 77, 2269-2286. doi:10.2307/2265730.

Botsford, J. L. (2002). A comparison of ecotoxicological tests. AtlaAlternatives to Laboratory Animals, 30, 539-550.

Boudouresque, C. F. (2008). Les espèces introduites et invasives en milieu marin, 3 edn. Marseille, France, GIS Posidonie Publisher.

Brown, J. H. (2014). Why are there so many species in the tropics? Journal of Biogeography, 41, 8-22. doi:10.1111/jbi.12228.

Cachet, N., Genta-Jouve, G., Ivanisevic, J., Chevaldonné, P., Sinniger, F., Culioli, G., et al. (2015). Metabolomic profiling reveals deep chemical divergence between two morphotypes of the zoanthid Parazoanthus axinellae. Scientific Reports, 5, 8282. doi:10.1038/ srep08282. 
Callaway, R. M., \& Ridenour, W. M. (2004). Novel weapons: invasive success and the evolution of increased competitive ability. Frontiers in Ecology and the Environment, 2, 436-443. doi:10.1890/1540-9295(2004)002[0436:nwisat]2.0.co;2.

Cardigos, F., Tempera, F., Ávila, S., Gonçalves, J., Colaço, A., \& Santos, R. S. (2006). Non-indigenous marine species of the Azores. Helgoland Marine Research, 60, 160-169. doi:10.1007/ s10152-006-0034-7.

Chainho, P., Fernandes, A., Amorim, A., Ávila, S. P., CanningClode, J., Castro, J. J., et al. (2015). Non-indigenous species in Portuguese coastal areas, coastal lagoons, estuaries and islands. Estuarine, Coastal and Shelf Science, 167, Part A, 199-211. doi:10.1016/j.ecss.2015.06.019.

Coley, P. D. \& Aide, T. M. (1991). Comparison of herbivory and plant defenses in temperate and tropical broad-leaved forests. In: Price, P. W., Lewinsohn, T. M., Fernandes, G. W., Benson, W. W. (eds) Plant-animal interactions: Evolutionary ecology in tropical and temperate regions. (pp25-49). John Wiley \& Sons.

Coley, P. D., \& Barone, J. A. (1996). Herbivory and plant defenses in tropical forests. Annual Review of Ecology \& Systematics, 27, 305-335. doi:10.1146/annurev.ecolsys.27.1.305.

Craft, J. D., Paul, V. J., \& Sotka, E. E. (2013). Biogeographic and phylogenetic effects on feeding resistance of generalist herbivores toward plant chemical defenses. Ecology, 94, 18-24. doi:10.1890/11-0873.1.

Cronin, G., \& Hay, M. E. (1996). Effects of light and nutrient availability on the growth, secondary chemistry, and resistance to herbivory of two brown seaweeds. Oikos, 77, 93-106. doi: $10.2307 / 3545589$.

del-Val, E., \& Armesto, J. J. (2010). Seedling mortality and herbivory damage in subtropical and temperate populations: Testing the hypothesis of higher herbivore pressure toward the tropics. Biotropica, 42, 174-179. doi:10.1111/j.1744-7429.2009.00554.x.

Deneb, K. (2001). Chemical defenses of marine organisms against solar radiation exposure Marine Chemical Ecology. Marine Science. (pp481-520). Boca Raton:CRC Press.

Dijoux, L. (2014). La diversité des algues rouges du genre Asparagopsis en Nouvelle-Calédonie : approches in situ et moléculaires., Université Pierre et Marie Curie.

Dijoux, L., Viard, F., \& Payri, C. (2014). The more we search, the more we find: discovery of a new lineage and a new species complex in the genus Asparagopsis. PLoS One, 9, e103826. doi:10.1371/journal.pone.0103826.

Dray, S., \& Dufour, A. B. (2007). The ade4 package: implementing the duality diagram for ecologists. Journal of Statistical Software, 22, 1-20.

Ejigu, B. A., Valkenborg, D., Baggerman, G., Vanaerschot, M., Witters, E., Dujardin, J. C., et al. (2013). Evaluation of normalization methods to pave the way towards large-scale LC-MS-based metabolomics profiling experiments. Omics-a Journal of Integrative Biology, 17, 473-485. doi:10.1089/omi.2013.0010.

Genovese, G., Faggio, C., Gugliandolo, C., Torre, A., Spano, A., Morabito, M., et al. (2012). In vitro evaluation of antibacterial activity of Asparagopsis taxiformis from the Straits of Messina against pathogens relevant in aquaculture. Marine Environmental Research, 73, 1-6. doi:10.1016/j.marenvres.2011.10.002.

González-Bergonzoni, I., Meerhoff, M., Davidson, T., Teixeirade Mello, F., Baattrup-Pedersen, A., \& Jeppesen, E. (2012). Meta-analysis shows a consistent and strong latitudinal pattern in fish omnivory across ecosystems. Ecosystems, 15, 492-503. doi:10.1007/s10021-012-9524-4.

Greff, S., Zubia, M., Genta-Jouve, G., Massi, L., Perez, T., \& Thomas, O. P. (2014). Mahorones, highly brominated cyclopentenones from the red alga Asparagopsis taxiformis. Journal of Natural Products, 77, 1150-1155. doi:10.1021/np401094h.
Hervé, M. (2016). RVAideMemoire: Diverse Basic Statistical and Graphical Functions. R package version 0.9-62. https:// CRAN.R-project.org/package=RVAideMemoire.

Ivanisevic, J., Perez, T., Ereskovsky, A. V., Barnathan, G., \& Thomas, O. P. (2011a). Lysophospholipids in the Mediterranean sponge Oscarella tuberculata: seasonal variability and putative biological role. Journal of Chemical Ecology, 37, 537-545. doi:10.1007/s10886-011-9943-2.

Ivanisevic, J., Thomas, O. P., Pedel, L., Pénez, N., Ereskovsky, A. V., Culioli, G., et al. (2011b). Biochemical trade-offs: evidence for ecologically linked secondary metabolism of the sponge Oscarella balibaloi. PLoS One, 6, e28059. doi:10.1371/journal. pone.0028059.

Johnson, B. T. (2005). Microtox ${ }^{\circledR}$ acute toxicity test. In: Blaise, C., Férard, J.-F. (eds) Small-scale Freshwater Toxicity Investigations. (pp69-105). Dordrecht:Springer.

Keane, R. M., \& Crawley, M. J. (2002). Exotic plant invasions and the enemy release hypothesis. Trends in Ecology \& Evolution, 17, 164-170. doi:10.1016/s0169-5347(02)02499-0.

Kladi, M., Vagias, C., \& Roussis, V. (2004). Volatile halogenated metabolites from marine red algae. Phytochemistry Reviews, 3, 337-366. doi:10.1007/s11101-004-4155-9.

Mannion, P. D., Upchurch, P., Benson, R. B. J., \& Goswami, A. (2014). The latitudinal biodiversity gradient through deep time. Trends in Ecology \& Evolution, 29, 42-50. doi:10.1016/j. tree.2013.09.012.

Martí, R., Fontana, A., Uriz, M. J., \& Cimino, G. (2003). Quantitative assessment of natural toxicity in sponges: toxicity bioassay versus compound quantification. Journal of Chemical Ecology, 29, 1307-1318. doi:10.1023/a:1024201100811.

Martí, R., Uriz, M. J., \& Turon, X. (2004). Seasonal and spatial variation of species toxicity in Mediterranean seaweed communities: correlation to biotic and abiotic factors. Marine Ecology-Progress Series, 282, 73-85. doi:10.3354/meps282073.

Micael, J., Parente, M. I., \& Costa, A. C. (2014). Tracking macroalgae introductions in North Atlantic oceanic islands. Helgoland Marine Research, 68, 209-219. doi:10.1007/s10152-014-0382-7.

Mineur, F., Arenas, F., Assis, J., Davies, A. J., Engelen, A. H., Fernandes, F., et al. (2015). European seaweeds under pressure: Consequences for communities and ecosystem functioning. Journal of Sea Research, 98, 91-108. doi:10.1016/j. seares.2014.11.004

Moles, A. T. (2013). Dogmatic is problematic: Interpreting evidence for latitudinal gradients in herbivory and defense. Ideas in Ecology and Evolution, 6, 1-4. doi:10.4033/iee.2013.6.1.c.

Moles, A. T., \& Ollerton, J. (2016). Is the notion that species interactions are stronger and more specialized in the tropics a zombie idea?. Biotropica. doi:10.1111/btp.12281.

Monro, K., \& Poore, A. G. B. (2009). The evolvability of growth form in a clonal seaweed. Evolution, 63, 3147-3157. doi:10.1111/j.1558-5646.2009.00802.x.

Mtolera, M. S. P., Collén, J., Pedersén, M., Ekdahl, A., Abrahamsson, K., \& Semesi, A. K. (1996). Stress-induced production of volatile halogenated organic compounds in Eucheuma denticulatum (Rhodophyta) caused by elevated $\mathrm{pH}$ and high light intensities. European Journal of Phycology, 31, 89-95. doi:10.1080/09670269600651241.

Nylund, G. M., Weinberger, F., Rempt, M., \& Pohnert, G. (2011). Metabolomic assessment of induced and activated chemical defence in the invasive red alga Gracilaria vermiculophylla. PLoS One, 6, e29359. doi:10.1371/journal.pone.0029359.

Oksanen, J., Blanchet, F. G., Kindt, R., Legendre, P., Minchin, P. R., O'Hara, R. B., et al. (2015). vegan: community ecology package. $\mathrm{R}$ package version 2.3-0. http://CRAN.R-project.org/ package $=$ vegan . 
Padilla-Gamino, J. L., \& Carpenter, R. C. (2007). Seasonal acclimatization of Asparagopsis taxiformis (Rhodophyta) from different biogeographic regions. Limnology and Oceanography, 52, 833842. doi: $10.4319 /$ lo.2007.52.2.0833.

Patti, G. J., Tautenhahn, R., \& Siuzdak, G. (2012). Meta-analysis of untargeted metabolomic data from multiple profiling experiments. Nature Protocols, 7, 508-516. doi:10.1038/ nprot.2011.454.

Paul, N. A. (2006). The ecology of chemical defence in a filamentous marine red alga. Sydney:University of New South Wales.

Paul, N. A., de Nys, R., \& Steinberg, P. D. (2006a). Chemical defence against bacteria in the red alga Asparagopsis armata: linking structure with function. Marine Ecology: Progress Series, 306, 87-101. doi:10.3354/meps306087.

Paul, N. A., de Nys, R., \& Steinberg, P. D. (2006b). Seaweed-herbivore interactions at a small scale: direct tests of feeding deterrence by filamentous algae. Marine Ecology Progress Series, 323, 1-9. doi:10.3354/meps323001.

Paul, N. A., Svensson, C. J., de Nys, R., \& Steinberg, P. D. (2014). Simple growth patterns can create complex trajectories for the ontogeny of constitutive chemical defences in seaweeds. PLoS One, 9, e86893. doi:10.1371/journal.pone.0086893.

Pelletreau, K. N. \& Targett, N. M. (2008). New perspectives for addressing patterns of secondary metabolites in marine macroalgae. In: Amsler, C. D. (ed) Algal Chemical Ecology. (pp121146). Berlin: Springer.

Pinedo, S., Arévalo, R., \& Ballesteros, E. (2015). Seasonal dynamics of upper sublittoral assemblages on Mediterranean rocky shores along a eutrophication gradient. Estuarine, Coastal and Shelf Science, 161, 93-101. doi:10.1016/j.ecss.2015.05.004.

Puglisi, M. P., Sneed, J. M., Sharp, K. H., Ritson-Williams, R., \& Paul, V. J. (2014). Marine chemical ecology in benthic environments. Natural Product Reports, 31, 1510.

Putz, A., \& Proksch, P. (2010). Chemical defence in marine ecosystems. Annual Plant Reviews, 39, 162-213. doi:10.1002/9781444318876.ch3.

R_Core_Team (2013). R: A language and environment for statistical computing. In: $\mathrm{R}$ Foundation for Statistical Computing. Vienna:R_Core_Team. http://www.R-project.org/.

Reverter, M., Perez, T., Ereskovsky, A. V., \& Banaigs, B. (2016). Secondary metabolome variability and inducible chemical defenses in the Mediterranean sponge Aplysina cavernicola. Journal of Chemical Ecology, 42, 60-70. doi:10.1007/s10886-015-0664-9.

Rogers, C. N., Nys, R. d., \& Steinberg, P. D. (2003). Ecology of the sea hare Aplysia parvula (Opisthobranchia) in New South Wales, Australia. Molluscan Research, 23, 185-198. doi:10.1071/ MR03004.

Schaffelke, B., \& Hewitt, C. L. (2007). Impacts of introduced seaweeds. Botanica Marina, 50, 397-417. doi:10.1515/ bot.2007.044.
Schemske, D. W., Mittelbach, G. G., Cornell, H. V., Sobel, J. M., \& Roy, K. (2009). Is there a latitudinal gradient in the importance of biotic interactions? Annual Review of Ecology, Evolution \& Systematics, 40, 245. doi:10.1146/annurev. ecolsys.39.110707.173430.

Simberloff, D., Martin, J. L., Genovesi, P., Maris, V., Wardle, D. A., Aronson, J., et al. (2013). Impacts of biological invasions: What's what and the way forward. Trends in Ecology \& Evolution, 28, 58-66. doi:10.1016/j.tree.2012.07.013.

Smith, C. A., Want, E. J., O’Maille, G., Abagyan, R., \& Siuzdak, G. (2006). XCMS: processing mass spectrometry data for metabolite profiling using nonlinear peak alignment, matching, and identification. Analytical Chemistry, 78, 779-787. doi:10.1021/ ac051437y.

Streftaris, N., \& Zenetos, A. (2006). Alien marine species in the Mediterranean - the 100 'Worst Invasives' and their impact. Mediterranean Marine Science, 7, 87-118. doi:10.12681/mms.180.

Szymanska, E., Saccenti, E., Smilde, A. K., \& Westerhuis, J. A. (2012). Double-check: validation of diagnostic statistics for PLSDA models in metabolomics studies. Metabolomics, 8, S3-S16. doi:10.1007/s11306-011-0330-3.

Targett, N., Coen, L., Boettcher, A., \& Tanner, C. (1992). Biogeographic comparisons of marine algal polyphenolics: evidence against a latitudinal trend. Oecologia, 89, 464-470. doi:10.1007/ bf00317150.

Van Alstyne, K., \& Paul, V. (1990). The biogeography of polyphenolic compounds in marine macroalgae: Temperate brown algal defenses deter feeding by tropical herbivorous fishes. Oecologia, 84, 158-163. doi:10.1007/bf00318266.

van der Kloet, F. M., Bobeldijk, I., Verheij, E. R., \& Jellema, R. H. (2009). Analytical error reduction using single point calibration for accurate and precise metabolomic phenotyping. Journal of Proteome Research, 8, 5132-5141. doi:10.1021/pr900499r.

Vergés, A., Paul, N. A., \& Steinberg, P. D. (2008). Sex and life-history stage alter herbivore responses to a chemically defended red alga. Ecology, 89, 1334-1343. doi:10.1890/07-0248.1.

Vermeij, G. J. (1978). Biogeography and adaptation: Patterns of marine life. (pp332). Cambridge:Harvard University Press.

Zanolla, M., Carmona, R., De la Rosa, J., Flagella, M., Souza-Egipsy, V. \& Altamirano, M. (2011). The seasonal cycle of Asparagopsis taxiformis (Rhodophyta, Bonnemeaisoniaceae): key aspects of the ecology and physiology of the most invasive macroalga in Southern Spain. Paper presented at the European Journal of Phycology.

Zenetos, A., Gofas, S., Morri, C., Rosso, A., Violanti, D., Garcia Raso, J., E., et al. (2012). Alien species in the Mediterranean Sea by 2012. A contribution to the application of European Union's Marine Strategy Framework Directive (MSFD). Part 2. Introduction trends and pathways, 13, 328-352. 